\title{
Determination of the Built-in Electric Field near Contacts to Polycrystalline CuInSe2 - Probing Local Charge Transport Properties by Photomixing
}

Y. Tang

Princeton Electronic Systems, Inc.

S. Dong, G.S. Sun, and R. Braunstein

Department of Physics, University of California

B. von Roedern

National Renewable Energy Laboratory

Presented at the National Center for

Photovoltaics Program Review Meeting

Denver, Colorado

September 8-11, 1998

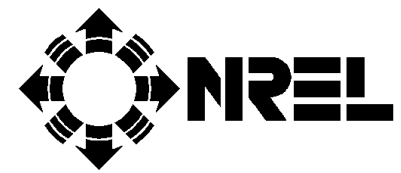

National Renewable Energy Laboratory 1617 Cole Boulevard Golden, Colorado 80401-3393 A national laboratory of the U.S. Department of Energy Managed by Midwest Research Institute for the U.S. Department of Energy under contract No. DE-AC36-83CH10093

Work performed under task number PV804401

November 1998 


\begin{abstract}
NOTICE
This report was prepared as an account of work sponsored by an agency of the United States government. Neither the United States government nor any agency thereof, nor any of their employees, makes any warranty, express or implied, or assumes any legal liability or responsibility for the accuracy, completeness, or usefulness of any information, apparatus, product, or process disclosed, or represents that its use would not infringe privately owned rights. Reference herein to any specific commercial product, process, or service by trade name, trademark, manufacturer, or otherwise does not necessarily constitute or imply its endorsement, recommendation, or favoring by the United States government or any agency thereof. The views and opinions of authors expressed herein do not necessarily state or reflect those of the United States government or any agency thereof.
\end{abstract}

Available to DOE and DOE contractors from:

Office of Scientific and Technical Information (OSTI)

P.O. Box 62

Oak Ridge, TN 37831

Prices available by calling 423-576-8401

Available to the public from:

National Technical Information Service (NTIS)

U.S. Department of Commerce

5285 Port Royal Road

Springfield, VA 22161

703-605-6000 or 800-553-6847

or

DOE Information Bridge

http://www.doe.gov/bridge/home.html 


\title{
Determination of the Built-in Electric Field near Contacts to Polycrystalline CuInSe - Probing Local Charge Transport Properties by Photomixing
}

\author{
Yi Tang ${ }^{+}$, Shirun Dong ${ }^{*}$, G. S. Sun ${ }^{*}$, R. Braunstein ${ }^{*}$ and B. von Roedern ${ }^{\#}$ \\ ${ }^{+}$Princeton Electronic Systems, Inc., P.O. Box 8627, Princeton, NJ 08543-8627 \\ "Department of Physics, University of California, Los Angeles, CA 90024 \\ "National Renewable Energy Laboratory, Golden, CO 80401-3393, USA
}

\begin{abstract}
The built-in electric field in polycrystalline $\mathrm{CuInSe}_{2}$ (CIS) near gold co-planar contacts was quantitatively revealed for the first time by the photomixing technique. A He-Ne laser beam was focused locally on the CIS sample near one of its contact. While both de dark and photo-currents showed ohmic behavior, the high frequency ac current was non-zero for zero applied dc bias, which reveals a built-in electric field of $\sim 1000 \mathrm{~V} / \mathrm{cm}$. The capability of the photomixing technique to probe local charge transport properties is expected to be very useful for, e.g., the quantitative evaluation of the quality of ohmic contacts and the investigation of electric field induced $p-n$ junction formation in CIS and related materials.
\end{abstract}

\section{INTRODUCTION}

Polycrystalline $\mathrm{CuInSe}_{2}$ (CIS) has attracted considerable interest due to its promising applications for solar cells ${ }^{1-4}$, as it has relatively high energy conversion efficiencies as compared with a-Si:H based solar cells and, especially, as they do not suffer from the Staebler-Wronski instability ${ }^{5}$.

In a series of previous papers, we have reported the determination of global charge transport properties, such as the majority carrier mobility and lifetime of a polycrystalline CIS sample ${ }^{6}$, as well as $\mathrm{c}-\mathrm{Si}^{7}$, a-Si: $\mathrm{H}^{8-11}, \mathrm{a}-\mathrm{SiC}: \mathrm{H}^{12}$ and a- $\mathrm{As}_{2} \mathrm{Te}_{3}{ }^{13}$ samples, using the photomixing technique ${ }^{11}$. In this letter, we report the determination of the built-in electric field in CIS near its gold co-planar contacts through probing local charge transport properties by photomixing. The capability of the photomixing technique to probe local charge transport properties is expected to be very useful for, e.g., the quantitative evaluation of the quality of ohmic contacts and the investigation of electric field induced $p-n$ junction formation in CIS and related materials ${ }^{14}$. The quality of ohmic contacts, in particular, is an important factor that affects the efficiency of CIS based solar cells ${ }^{15}$. 


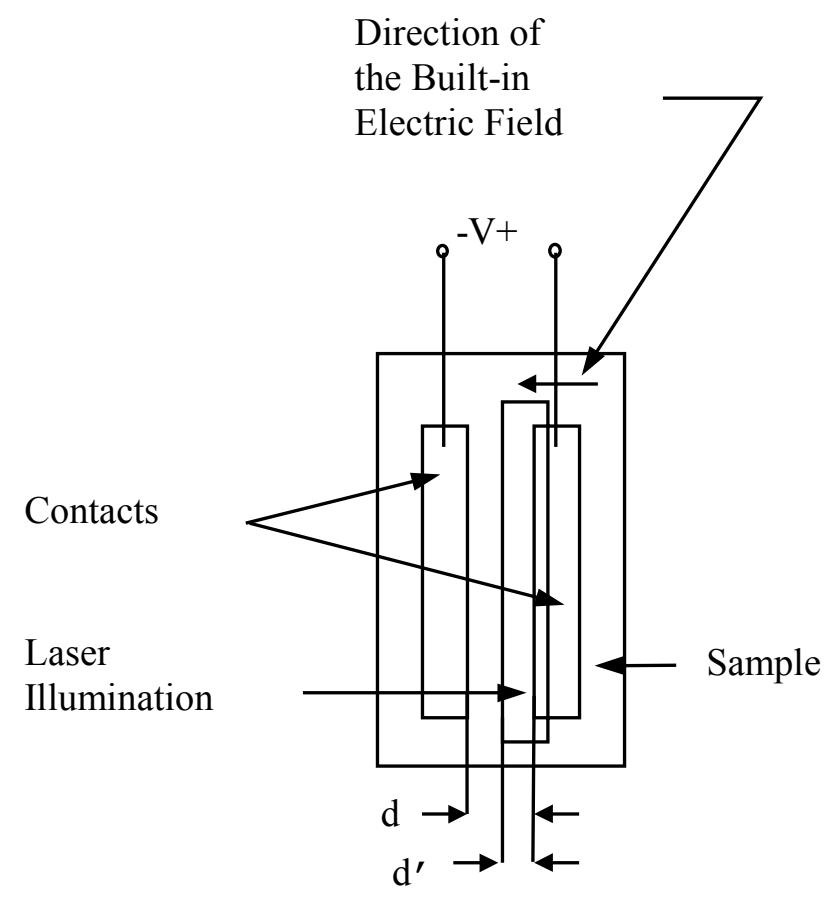

FIGURE 1. Schematic diagram of the CIS sample.

\section{EXPERIMENTAL}

The photomixing technique ${ }^{11}$ employed is based on the idea of heterodyne detection for photoconductors. When two similarly polarized monochromatic optical beams of slightly different frequencies are incident upon a photoconductor, the generation rate of electron-hole pairs and therefore the photocurrent produced, when a dc bias is applied, will contain components resulting from the square of the sum of the incident electrical fields. Consequently, a photocurrent composed of a dc and a microwave (photomixing) current due to the beat frequency of the incident fields will be produced; these two photocurrents allow determinations of the drift mobility and lifetime of the photogenerated carriers. In practice, multiple longitudinal modes of a single laser were used. By focusing the laser beam to a local area, local charge transport properties can be studied.

The polycrystalline CuInSe $\mathrm{S}_{2}$ sample (n-type) used for this work was provided by the National Renewable Energy Laboratory (NREL) and was produced by a recrystallization process from a precursor resulting in large grain $\mathrm{CuInSe}_{2}$ films ${ }^{2}$. This sample was measured to be between 3.4 and $4 \mu \mathrm{m}$ thick and has the following composition: $20 \% \mathrm{Cu}, 29 \% \mathrm{In}, 51 \% \mathrm{Se}$. Co-planar gold contacts with separation of $0.3 \mathrm{~mm}$ were evaporated onto the sample. The photomixing signal was obtained by using a He-Ne laser $(632.8 \mathrm{~nm})$. The light intensity at the sample surface was about 23 $\mathrm{mW} / \mathrm{cm}^{2}$ and the applied dc bias ranged from $-20 \mathrm{~V}$ to $20 \mathrm{~V}$. The photomixing signal 
(at $252 \mathrm{MHz}$ ) resulting from the mixing of the longitudinal modes of the laser was measured by a Tektronic 492P Spectrum Analyzer.
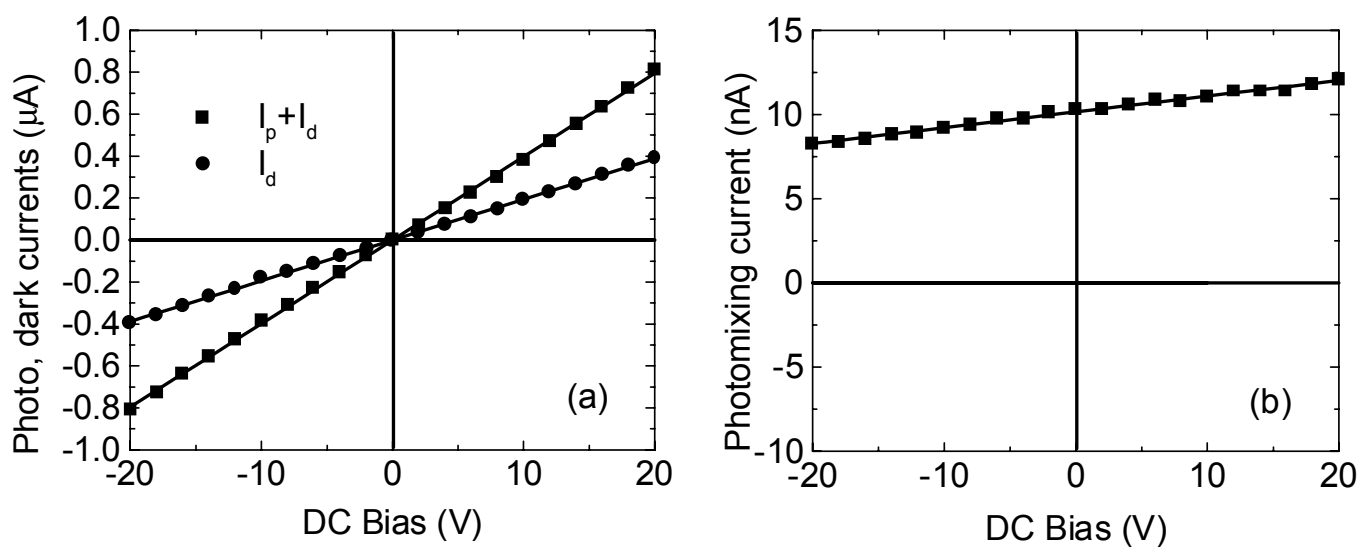

FIGURE 2. (a) Dark current $\left(I_{d}\right)$, sum of dark and photocurrent $\left(I_{d}+I_{p}\right)$ and (b) photomixing current $\left(\mathrm{I}_{\text {mix }}\right)$ versus applied de bias. Both the dark current and the photocurrent show ohmic behavior, but the photomixing current shows a non-ohmic behavior, since it is non-zero at zero dc bias. This indicates the existence of a built-in electrical field near the contact. The straight lines are the least square fit to the data. The built-in electrical field near the contact was found to be $\sim 1000 \mathrm{~V} / \mathrm{cm}$.

\section{RESULTS AND DISCUSSION}

When the sample area in-between the co-planar contacts was uniformly illuminated by the laser, ohmic behaviors for the dc dark current $\left(I_{d}\right)$, dc photocurrent $\left(I_{p}\right)$, and the photomixing current $\left(\mathrm{I}_{\text {mix }}\right)$ were observed through the $\mathrm{I}-\mathrm{V}$ measurements. However, when the laser beam was line focused (with width of $\sim 0.2 \mathrm{~mm}$ ) parallel to the longer dimension of the contacts (as shown in Figure 1), as the laser beam was scanned across the interfaces between the sample and the coplanar contacts, non-zero photomixing currents $\left(\mathrm{I}_{\mathrm{mix}}\right)$ were observed under zero applied dc bias, which reveals a non-ohmic behavior, or more specifically, the existence of a built-in electric field near the contacts. As the laser beam was kept near one of the contacts such that the photomixing currents $\left(\mathrm{I}_{\text {mix }}\right)$ was maximized under zero applied dc bias, the I-V measurements were performed for $I_{d}, I_{d}+I_{p}$, and $I_{\text {mix }}$, with the results shown in Figure 2. The former two currents showed ohmic behavior, while the photomixing currents $\left(\mathrm{I}_{\text {mix }}\right)$ showed a non-ohmic behavior. The straight lines in Figure 2 are the least squares fits to the currents, from which the value of the applied dc bias needed to offset the a built-in electric field (for zero $\mathrm{I}_{\text {mix }}$ ) was found to be $-87 \mathrm{~V}$.

The magnitude of the built-in electric field $E^{\prime}$ can be estimated as:

$$
E^{\prime}=\frac{\left|V^{\prime}\right|}{d^{\prime}}=\left(1-\frac{\left(I_{p}+I_{d}\right)\left(d-d^{\prime}\right)}{I_{d} d}\right) \frac{|V|}{d^{\prime}} \approx 1000 \mathrm{~V} / \mathrm{cm}
$$


where $V$ and $V^{\prime}$ are applied dc bias voltages across the two contacts and across the laser illuminated area, $d$ and $d^{\prime}$ are the separation between the two contacts and the width of the laser illuminated area (Figure 1).

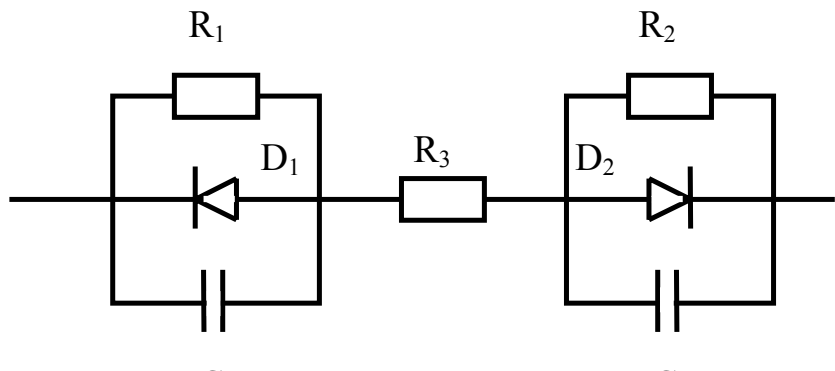

$\mathrm{C}_{1} \quad \mathrm{C}_{2}$

Figure 3. The equivalent circuit for the sample. The built-in electrical fields in the Schottky barriers near the two contacts are represented by two Schottky diodes $D_{1}$ and $D_{2} ; R_{1}, R_{2}$ and $C_{1}, C_{2}$ are the effective resistance and capacitance of the two Schottky barriers; and $\mathrm{R}_{3}$ is the effective resistance of the bulk sample in-between the contacts.

This built-in electrical field can be explained by the common Schottky barrier effect between semiconductors and their metal contacts. The equivalent circuit for the sample is shown in Figure 3. The built-in electrical fields in the Schottky barriers near the two contacts are represented by two Schottky diodes $D_{1}$ and $D_{2} ; R_{1}, R_{2}$ and $C_{1}, C_{2}$ are the effective resistance and capacitance of the two Schottky barriers; and $R_{3}$ is the effective resistance of the bulk sample in-between the contacts.

The lack of non-ohmic behavior for the dc currents in the presence of the built-in electric fields is due to the fact that the non-ohmic effect of the built-in electric field near one contact is largely canceled by the built-in electric field (in the opposite direction) near the other contact. Such cancellation, however, does not occur for the high frequency photomixing current (at $252 \mathrm{MHz}$ ), as it can go through the barrier capacitance. If the barrier width is estimated as $\sim 0.1 \mu \mathrm{m}$, then the barrier height is only about $10 \mathrm{mV}$.

\section{SUMMARY}

In summary, the built-in electric field in polycrystalline $\mathrm{CuInSe} \mathrm{I}_{2}$ near the gold coplanar contacts was quantitatively revealed for the first time by the photomixing technique, which is of significant technological importance, as it provides a means to quantitatively evaluate the quality of ohmic contacts, an important factor that affects the efficiency of CIS based solar cells. This also demonstrated the capability of the photomixing technique for probing local charge transport properties, which would be useful for the investigation of electric field induced $p$-n junction formation in CIS and related materials. In addition, this may explain why in CIS based solar cells there are 
often distortions observed in the light I(V)-curves and an unexplained nonsuperposition of photo- and dark currents ${ }^{16}$.

\section{ACKNOWLEDGMENTS}

This work was supported by the National Renewable Energy Laboratory subcontract XAN-4-13318-10. We thank Dr. R. Noufi, and Dr. J. Tuttle for supplying the CIS samples.

\section{REFERENCES}

1. A N. Y. Samaan, R. Vaidhyanathan, R. Noufi, and R. D. Tomlinson, Solar Cells 16,181 (1986).

2. A.M. Gabor, J.R. Tuttle, D.S. Albin, M.A. Contreras, R. Noufi, and A.M. Hermann, Appl. Phys. Lett. 65, 198 (1994).

3. J.-B. Yoo, A.L. Fahrenbruch, and R. H. Bube, J. Appl. Phys. 68, 4694 (1990).

4. H. J. Moller, Solar Cells 31, 77 (1991).

5. D. L. Staebler and C. R. Wronski, Appl. Phys. Lett. 31, 292 (1985).

6. Yi Tang and R. Braunstein, Appl. Phys. Lett. 63, 2393 (1993).

7. E. R. Geissinger, R. Braunstein, S. Dong, and B. G. Martin, J. Appl. Phys. 69, 1469 (1991).

8. Yi Tang, R. Braunstein, and B. von Roedern, Mat. Res. Soc. Symp. Proc. 258, 735 (1992).

9. Yi Tang, R. Braunstein, B. von Roedern, and F. R. Shapiro, Mat. Res. Soc. Symp. Proc. 297, 407 (1993).

10. Yi Tang, S. Dong, R. Braunstein and B. von Roedern, Appl. Phys. Lett. 68, 640 (1996).

11. Yi Tang and R. Braunstein, J. Appl. Phys. 79, 850 (1996).

12. Yi Tang and R. Braunstein, Appl. Phys. Lett. 66, 721 (1995).

13. R. Braunstein and Yi Tang, Proceeding of 21 st International Conference on Physics of Semiconductors (August, 1992), Beijing, China (World Scientific, Singapore, 1992), Vol. 1, P. 269.

14. L. Chernyak and D. Cahen, Appl. Phys. Lett. 65, 427 (1994).

15. E. Moons, T. Engelhard, and D. Cahen, J. Electronic Materials 22, 275 (1993).

16. I.L. Eisgruber, J.E. Granata, J.R. Sites, J. Hou, and J. Kessler, accepted for publication in Solar Energy Materials and Solar Cells (6/1998). 